\title{
Recurrent massive hemoptysis in a patient with cystic fibrosis: balloon assisted Onyx embolization after bronchial artery coil recanalization
}

\author{
Raghav R. Mattay ${ }^{*}$ D, Richard Shlansky-Goldberg and Bryan A. Pukenas
}

\begin{abstract}
Background: Although not standard of care, Cystic Fibrosis patients with recurrent hemoptysis occasionally have coil embolization of bronchial arteries. In the event of recanalization of these arteries in this specific subset of patients, the presence of indwelling coils makes the prospect of conventional particle embolization more difficult, preventing both adequate catheterization of the coiled segment and reflux of the particles.

Case presentation: In this report, we describe a case of bronchial artery embolization of a complex Cystic Fibrosis patient with massive hemoptysis from recanalized coiled bronchial arteries utilizing a Scepter Balloon Catheter ${ }^{\circledR}$ (Microvention Terumo, USA) in administration of the liquid embolic agent Onyx ${ }^{\circledast}$ (Medtronic, USA).

Conclusions: The Scepter occlusion balloon catheter allowed for careful placement of the tip within the interstices of the pre-existing coils, allowing for Onyx injection directly into the coil mass without reflux, reconfirming the benefits of Onyx embolization in bronchial artery embolization and providing evidence that the Scepter occlusion balloon catheter should be added to the armamentarium of devices used in complex bronchial artery embolization for Cystic Fibrosis patients with massive hemoptysis.
\end{abstract}

Keywords: Bronchial artery embolization, Balloon catheter, Onyx, Cystic fibrosis

\section{Background}

Intercostal and bronchial artery embolization with particles is a commonly used procedure to treat massive hemoptysis in patients with Cystic Fibrosis (CF). Occasionally, while not standard of care, coils may be used but prevent repeat embolization when needed. Patients with coils and recurrent hemoptysis may have recanalized arteries making the prospect of conventional particle embolization more difficult due to inability to safely catheterize the coiled segment and retreatment. Liquid embolic agents such as Onyx ${ }^{\circ}$ (Medtronic, USA), often used in neuro-interventional procedures (Brassel and Meila 2015), have been shown to be effective in some cases of refractory massive hemoptysis in patients with CF where conventional particle embolization has failed (Ao et al. 2013). In certain situations, the injection of Onyx through a microcatheter can be technically challenging, with resultant complications including Onyx reflux and non-target embolization. In order to mitigate complications, a balloon catheter can be used to augment flow of Onyx (Paramasivam et al. 2013). We describe our experience of administration of liquid Onyx through a Scepter ${ }^{\circ} \mathrm{XC}$ balloon catheter (Microvention Terumo, USA) into a recanalized intercostal artery with indwelling coils to successfully treat a patient with refractory massive hemoptysis.

\footnotetext{
* Correspondence: rrmattay@gmail.com

Department of Radiology, Hospital of the University of Pennsylvania, 3400 Spruce Street, Philadelphia, PA 19104, USA
}

\section{Springer Open}

(c) The Author(s). 2021 Open Access This article is licensed under a Creative Commons Attribution 4.0 International License, which permits use, sharing, adaptation, distribution and reproduction in any medium or format, as long as you give appropriate credit to the original author(s) and the source, provide a link to the Creative Commons licence, and indicate if changes were made. The images or other third party material in this article are included in the article's Creative Commons licence, unless indicated otherwise in a credit line to the material. If material is not included in the article's Creative Commons licence and your intended use is not permitted by statutory regulation or exceeds the permitted use, you will need to obtain permission directly from the copyright holder. To view a copy of this licence, visit http://creativecommons.org/licenses/by/4.0/. 


\section{Case presentation}

The patient was a 23 year-old Caucasian female with a history of CF and persistent hemoptysis, preventing her from being able to lie supine. She presented for semiemergent bronchial artery embolization treatment for her hemoptysis. The patient had undergone coil embolization previously for the same condition at an outside hospital.

Preoperative examination revealed no contraindications to bronchial artery embolization and patient was placed under conscious sedation throughout the procedure. A 5-French Cobra catheter was placed in the descending aorta through the femoral artery using standard Seldinger technique.

The diagnostic portion of the examination via conventional contrast angiography demonstrated tortuous and ectatic vessels from several bronchial arteries perfusing the upper lobe of the right lung, and right bronchial to pulmonary arterial shunting (Fig. 1a). The fourth intercostal artery was selectively catheterized with a diagnostic catheter and a superselective angiogram demonstrated multiple recanalized coils in the feeding artery (Fig. 1b). Additionally a prominent spinal artery originating from the bronchial artery was detected (Fig. 1c).

Conventional particle embolization was attempted, but the indwelling coils prevented complete filling of the tortuous, ectatic vessels distal to the coils and caused reflux of the particles (Fig. 2). A decision was then made to embolize this branch with Onyx 18. To facilitate this, the 5-French Cobra catheter was replaced with a Neuron $053^{\circ}$ guide catheter (Penumbra, USA), which was positioned into the intercostal artery. A $4 \times 11 \mathrm{~mm}$ Scepter occlusion balloon microcatheter was then prepared

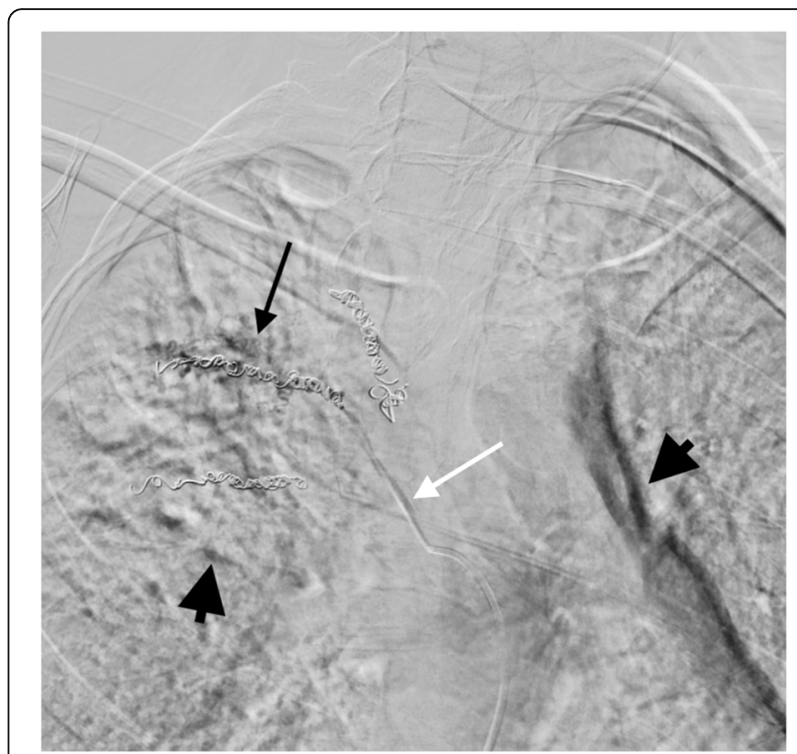

Fig. 2 Slight RAO projection of digital subtraction arteriogram during attempted microparticle infusion with evidence of reflux along the microcatheter located in the fourth intercostal artery (white arrow). There is some minor, incomplete filling of the tortuous, ectatic vessels distal to the coils (black arrow). Large black arrowheads demonstrate breathing artifact from digital subtraction angiography

using standard technique and positioned with its tip within the interstices of the coil mass (Fig. 3).

The catheter was then purged with Dimethyl sulfoxide (DMSO). Following DMSO injection, the balloon was inflated and Onyx 18, using common preparation technique (Guimaraes and Wooster 2011), was injected under continuous fluoroscopic guidance. Onyx was

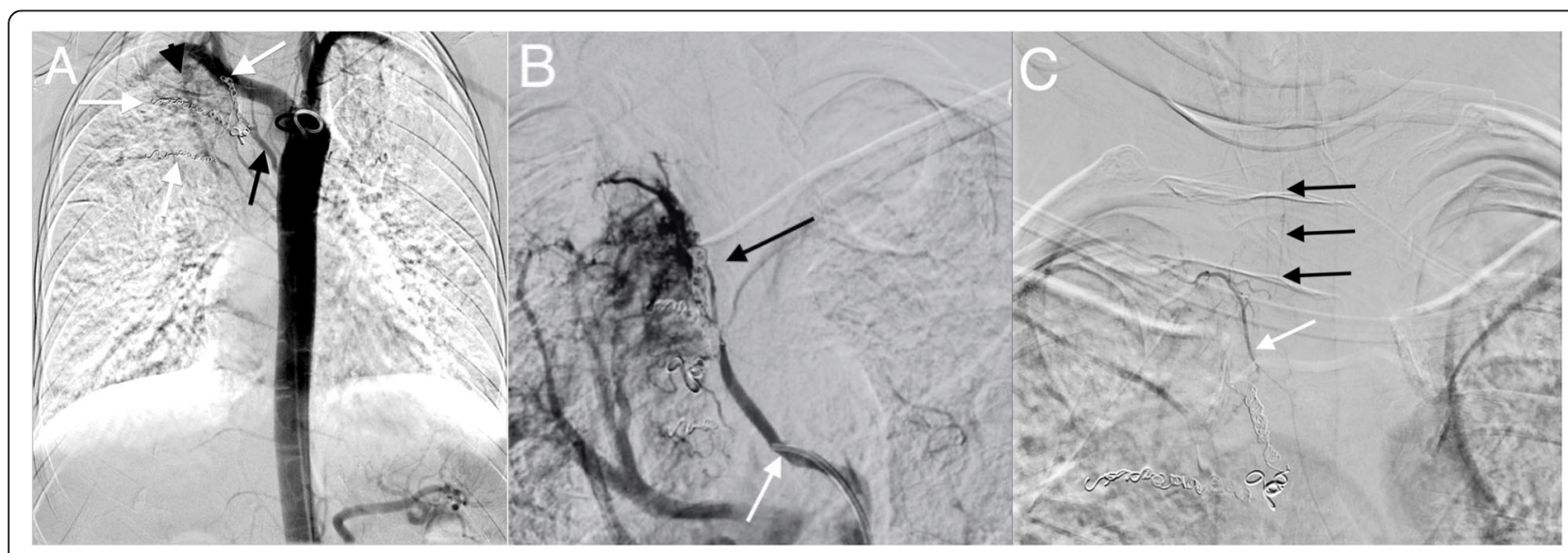

Fig. 1 a Thoracic AP digital subtraction aortogram shows a dominant right intercostal bronchial trunk (black arrow) and additional hypertrophied right intercostal arteries, all of which had been previously embolized with coils (white arrows). Tortuous ectatic vessels are also present arising from the upper thoracic segmental arteries (black arrowhead). b Magnified right anterior oblique (RAO) superselective angiogram with microcatheter in the right fourth intercostal artery (white arrow) demonstrates multiple recanalized coils (black arrow). c Slight RAO superselective angiogram of a branch of the prominent intercostal bronchial trunk (white arrow) showed a spinal artery branch (black arrows). This bronchial artery was not embolized 


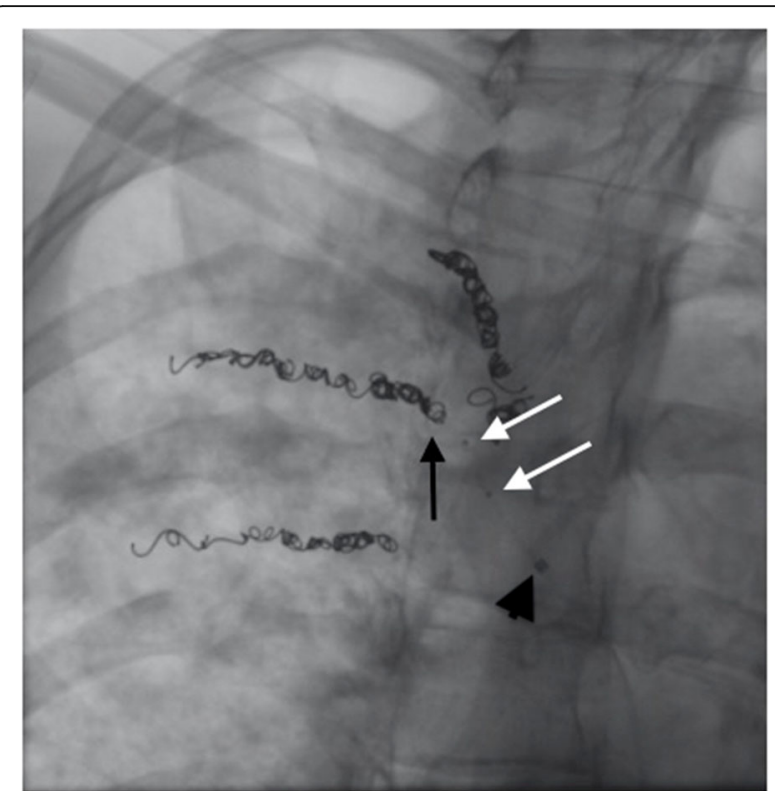

Fig. 3 Magnified slight RAO fluoroscopic image demonstrating an uninflated $4 \times 11 \mathrm{~mm}$ Scepter XC balloon catheter with its tip (black arrow) within the interstices of the coil mass. White arrows point to the proximal and distal radio-opaque markers showing the location of the uninflated balloon of the Scepter XC balloon catheter. The black arrowhead shows the radio-opaque distal tip of the Neuron $6 \mathrm{~F}$ 053 Delivery Catheter ${ }^{\circledast}$ (Penumbra, USA)

injected through the existing coil mass until there was filling adequate filling of the feeding pedicle and multiple collateral vessels within the lung (Fig. 4). Careful inspection of both roadmap and native (non-subtracted) imaging was performed during slow Onyx injection to ensure adequate penetration into the ectatic vessels without proximal reflux into the parent intercostal artery. The balloon was inflated and Onyx was injected for approximately $14 \mathrm{~min}$. During Onyx injection, the patient reported mild pain that quickly resolved, without further intervention.

At this point, the balloon catheter was deflated by aspirating the balloon port and removed uneventfully. Postembolization arteriography demonstrated no residual flow to the diseased portion of the lung from the targeted feeding pedicle (Fig. 5) and an Onyx cast filling of numerous branches originating from the fourth intercostal bronchial trunk without casting of the pulmonary arteries.

Next, the right fifth intercostal artery was selected and further diagnostic arteriography was carried out. Although coils were present, a proximal branch could be embolized in the conventional fashion with 700-900 microspheres. Post embolization selective arteriography demonstrated no residual flow from the fifth intercostal artery and appropriate pruning of embolized vessels. The catheters and wires were then removed from the

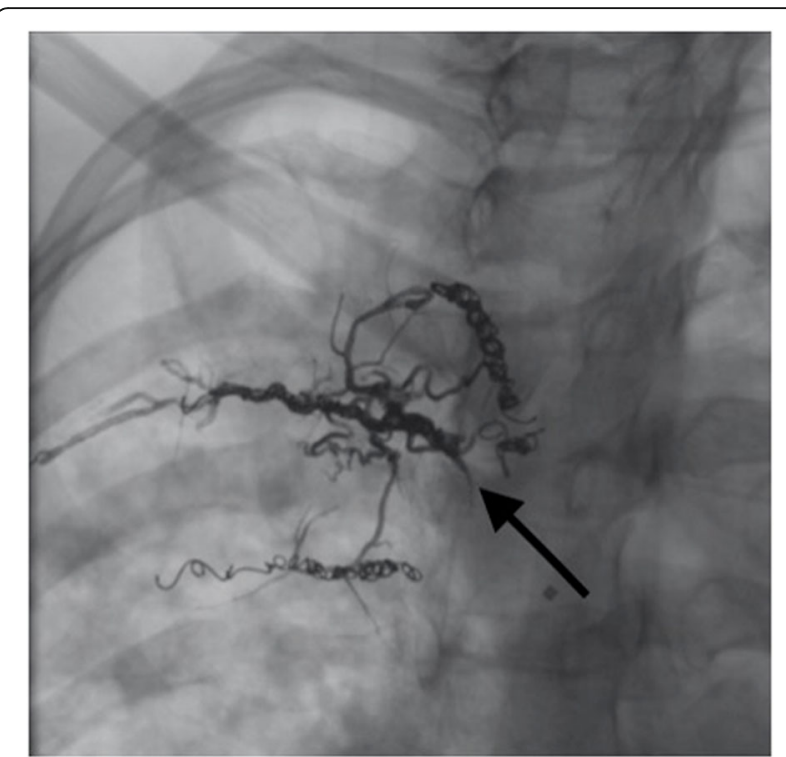

Fig. 4 Magnified slight RAO fluoroscopic image demonstrating adequate filling of the feeding pedicle and multiple collateral vessels with radio-opaque Onyx

patient and hemostasis was achieved using manual compression. Follow up at 6 and 12 months revealed no evidence of further hemoptysis or other complications. The patient later underwent successful bilateral lung transplantation.

\section{Conclusions}

Hemoptysis is a common complication of CF, and occurs in approximately $9.1 \%$ of patients (Flume et al.

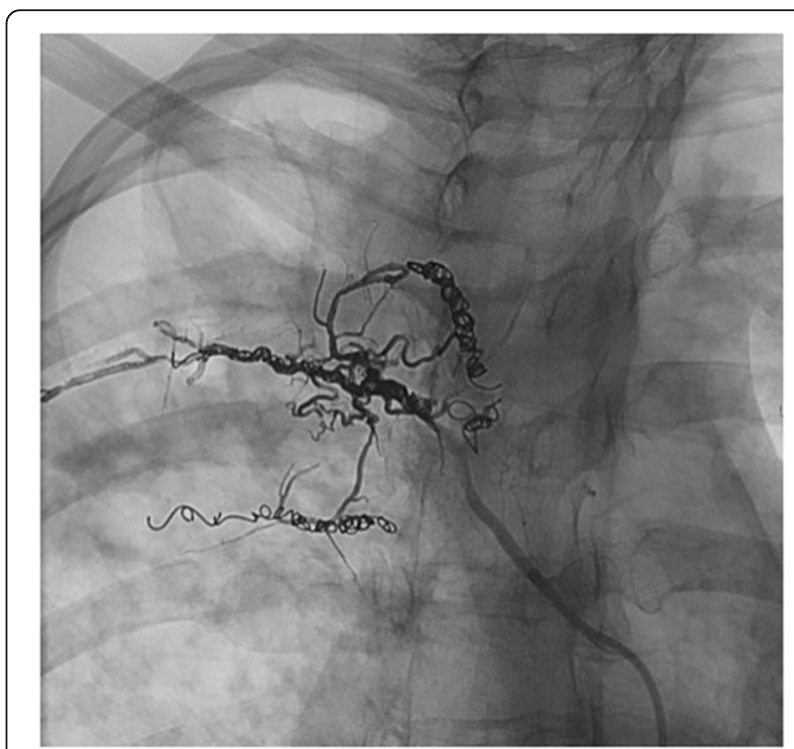

Fig. 5 Superselective slight RAO postembolization arteriography demonstrated no residual flow to the diseased portion of the lung from the targeted feeding pedicle 
2005). Bronchial artery embolization (BAE) is the recommended procedure for clinically unstable patients with massive hemoptysis according to the Cystic Fibrosis Foundation consensus statement (Schidlow et al. 1993). Despite the effectives of embolization in controlling acute hemoptysis, adults with cystic fibrosis who have undergone BAE for hemoptysis have a much higher risk of respiratory function worsening, death, and need for lung transplantation. (Vidal et al. 2006) Moreover, while a life-saving procedure, recurrence of hemoptysis after BAE is not uncommon and occurs in $18 \%$ in those patients with initial life-threatening hemoptysis (GarciaOlivé et al. 2014) and up to $55 \%$ in a cohort of young patients with CF (Barben et al. 2002).

In general, two different types of materials are used in endovascular embolization: solid and liquid agents. Currently, solid agents including Polyvinyl alcohol particles and coils, all lead to mechanical obliteration of the vessel through flow deceleration and subsequent thrombosis (Brassel and Meila 2015; Hurt and Simmonds 2012). The liquid embolic agents include adhesive materials and non-adhesive materials such as alcohol copolymers (Onyx) and n-butyl-2-cyanoacrylate (NBCA) glue. Liquid embolic agents have the advantage of filling a vascular area homogenously and give the operator better control, which decreases the risk and frequency of recanalization when compared to the use of solid embolization materials such as PVA particles. (Brassel and Meila 2015; Pierot et al. 2013). Onyx has been shown to have penetration into capillary vessels as small as $5 \mu \mathrm{m}$ in diameter (Natarajan et al. 2009), increasing durability and effectiveness for hemoptysis treatment.

Within the realm of BAE, particles or microspheres are the most commonly used embolic agents (Corr 2005; White Jr. 1999). Coil embolization is not recommended and rarely performed for BAE, as presence of coils in the bronchial arteries block future endovascular catheterization and treatment (Monroe et al. 2018), however, coil embolization can be used for short term results. In one study, recurrent hemoptysis from a previously embolized bronchial artery with or without coils occurred a total of $22.2 \%$ of the time, noting that approximately a third of these recanalized arteries contained coils (Garcia-Olivé et al. 2014). Similarly, Sagara et al. (Sagara et al. 1998) found an exceedingly high recanalization rate in pulmonary AVMs embolized with coils (57\%), furthermore justifying that this embolization agent should be avoided in patients with life-threatening hemoptysis (Sagara et al. 1998), especially in patients with CF who are known to have a higher recurrence rate for hemoptysis.

In this case, the presence of indwelling recanalized coils in the bronchial artery caused reflux of PVA particles during the attempted embolization of the fourth intercostal artery. Since adequate control could not be obtained and superselective catheterization showed multiple tortuous vessels feeding the diseased portion of the right upper lung distal to the coils, a decision was made to embolize with a liquid embolic agent. While other liquid embolic agents such as NBCA are increasingly being used in BAE (Woo et al. 2013; Abdulmalak et al. 2018) with successful results, we chose Onyx for embolization through the Scepter balloon. The inflated Scepter balloon created a "plug" and allowed for more controlled and deeper penetration into distal bronchial artery with indwelling coils without the need of robust forward flow, which is required in the much harder to control NBCA (Urbano et al. 2014). While typically reserved for neurointervention (Linfante and Wakhloo 2007), there have been a few reports of the utility of Onyx in BAE (Ao et al. 2013; Bommart et al. 2012; Adamus Nürnberg et al. 2010; Khalil et al. 2010; Ayx et al. 2017) with low recurrence rates for hemoptysis after embolization. Additionally, BAE with Onyx has few adverse reactions and patients have reported a high tolerance (Adamus Nürnberg et al. 2010; Khalil et al. 2010).

Since Onyx is a liquid agent, a rapid administration may result in reflux and some retrograde embolization, which can compromise normal vasculature and lead to entrapment. Attempting to pull the microcatheter can lead to catheter stretching, rupture, and occasionally rupture of the feeding vessel, causing further hemorrhage (Paramasivam et al. 2013). Development of an Onyx "plug" technique in which a proximal plug is allowed to form at the microcatheter tip before anterograde injection has been shown to allow for prevention of some reflux, however this has shown to lead to increased fluoroscopic times (Weber et al. 2007; Velat et al. 2008).

In this case, in order to minimize reflux of Onyx, a Scepter balloon catheter was used. Since the 1970's, balloon catheters have been used in neurointerventional procedures allowing for distal fluid delivery while the balloon remains inflated which forms a proximal plug and prevents reflux of the embolization agents (Kerber 1976). More recently Rose et al. showed the utility of balloon occlusion-assisted delivery of Onyx for some peripheral arterial applications including hemorrhage (Rose et al. 2020). The Scepter balloon catheter in particular has a variety of features that makes it very useful in liquid embolization. Firstly, the catheter is DMSO compatible, allowing it to be used with Onyx. Secondly, it has a coaxial double lumen with two corresponding ports, one to inject and the other to inflate the balloon separately. The balloon of the Scepter catheter is also extremely pliable and conforms well to the shape of the vessel and can even herniate into proximal feeders forming a better seal (Paramasivam et al. 2013). The catheter 
itself is also very flexible and navigable with a $5 \mathrm{~mm}$ tip that can be steam shaped to assist in directional control. In this particular example, the Scepter occlusion balloon catheter allowed for careful placement of the tip within the interstices of the pre-existing coils, allowing for Onyx injection directly into the coil mass without reflux.

In this example, we reconfirm the benefits of Onyx embolization in BAE, especially in attempts to embolize recanalized coils. It also provides evidence that the Scepter occlusion balloon catheter should be added to the armamentarium of devices used in complex BAE for CF patients with massive hemoptysis.

\section{Abbreviations}

CF: Cystic fibrosis; BAE: Bronchial artery embolization; DMSO: Dimethyl sulfoxide

\section{Acknowledgments}

None.

\section{Authors' contributions}

All authors contributed to the conception of the work, writing/revision of the manuscript and approved the final version of the manuscript.

\section{Funding}

None.

\section{Availability of data and materials}

All data generated or analysed during this study are included in this published article.

\section{Ethics approval and consent to participate}

Need for IRB approval was waived due to patient number.

\section{Consent for publication}

Written consent was obtained from all individual participants included in the study.

\section{Competing interests}

The authors declare no conflict of interest related to the current manuscript.

Received: 17 September 2020 Accepted: 22 December 2020

Published online: 05 January 2021

\section{References}

Abdulmalak G, Chevallier O, Falvo N, Di Marco L, Bertaut A, Moulin B, Abi-Khalil C, Gehin S, Charles PE, Latournerie M, Midulla M, Loffroy R (2018) Safety and efficacy of transcatheter embolization with Glubran 2 cyanoacrylate glue for acute arterial bleeding: a single-center experience with 104 patients. Abdom Radiol (NY) 43(3):723-733. https://doi.org/10.1007/s00261-017-1267-4 PMID: 28765976

Adamus Nürnberg R, Uder Erlangen M, Kleinschmidt T, Detmar K, Bolte R, Stein H, Loose RW (2010) Embolization of acute abdominal and thoracic hemorrhages with ethylene vinyl alcohol copolymer (Onyx): initial experiences with arteries of the body trunk. Rofo. 182(10):900-904. https:// doi.org/10.1055/s-0029-1245572

Ao M, Guo SL, Zhang XD, Li YL, Li Y, Li Q (2013) First case in China: Onyx for bronchial artery embolization in treatment of refractory massive hemoptysis in one case. J Thorac Dis 5(3):E98-E102. https://doi.org/10.3978/j.issn.20721439.2013.05.20

Ayx I, Müller-Wille R, Wohlgemuth WA, Pfeifer M, Lepiorz M, Hubauer H, Goessmann H, Stroszczynski C, Zorger N (2017) Treatment of acute hemoptysis by bronchial artery embolization with the liquid embolic agent ethylene vinyl alcohol copolymer. J Vasc Interv Radiol 28(6):825-831. https:// doi.org/10.1016/j.jvir.2016.12.1226 Epub 2017 Mar 6. PMID: 28279585

Barben J, Robertson D, Olinsky A, Ditchfield M (2002) Bronchial artery embolization for hemoptysis in young patients with cystic fibrosis. Radiology. 224(1):124-130. https://doi.org/10.1148/radiol.2241010654 PMID: 12091671
Bommart S, Bourdin A, Giroux MF, Klein F, Micheau A, Bares VM, Kovacsik H (2012) Transarterial ethylene vinyl alcohol copolymer visualization and penetration after embolization of life-threatening hemoptysis: technical and clinical outcomes. Cardiovasc Intervent Radiol 35(3):668-675. https://doi.org/ 10.1007/s00270-011-0270-3 Epub 2011 Sep 8. PMID: 21901579

Brassel F, Meila D (2015 Oct) Evolution of embolic agents in interventional neuroradiology. Clin Neuroradiol 25(Suppl 2):333-339. https://doi.org/10. 1007/s00062-015-0419-6

Corr PD (2005) Bronchial artery embolization for life-threatening hemoptysis using tris-acryl microspheres: short-term result. Cardiovasc Intervent Radiol 28(4):439-441. https://doi.org/10.1007/s00270-004-0227-x PMID: 15959698

Flume PA, Yankaskas JR, Ebeling M, Hulsey T, Clark LL (2005) Massive hemoptysis in cystic fibrosis. Chest. 128(2):729-738

Garcia-Olivé I, Sanz-Santos J, Centeno C, Radua J, Andreo F, Sampere J, Michavila JM, Muchart J, Stojanovic Z, Ruiz Manzano J (2014) Predictors of recanalization in patients with life-threatening hemoptysis requiring artery embolization. Arch Bronconeumol 50(2):51-56. https://doi.org/10.1016/j. arbres.2013.06.003 English, Spanish. Epub 2013 Aug 7. PMID: 23932187

Guimaraes M, Wooster M (2011 Sep) Onyx (ethylene-vinyl alcohol copolymer) in peripheral applications. Semin Intervent Radiol 28(3):350-356. https://doi.org/ $10.1055 / \mathrm{s}-0031-1284462$

Hurt K, Simmonds NJ (2012) Cystic fibrosis: management of haemoptysis. Paediatr Respir Rev 13(4):200-205. https://doi.org/10.1016/j.prrv.2012.01.003

Kerber C (1976) Balloon catheter with a calibrated leak. A new system for superselective angiography and occlusive catheter therapy. Radiology. 120(3): $547-550$

Khalil A, Fartoukh M, Bazot M, Parrot A, Marsault C, Carette MF (2010) Systemic arterial embolization in patients with hemoptysis: initial experience with ethylene vinyl alcohol copolymer in 15 cases. AJR Am J Roentgenol 194(1): W104-W110. https://doi.org/10.2214/AJR.09.2379

Linfante I, Wakhloo AK (2007) Brain aneurysms and arteriovenous malformations: advancements and emerging treatments in endovascular embolization. Stroke. 38(4):1411-1417

Monroe EJ, Pierce DB, Ingraham CR, Johnson GE, Shivaram GM, Valji K (2018) An Interventionalist's guide to hemoptysis in cystic fibrosis. Radiographics. 38(2): 624-641. https://doi.org/10.1148/rg.2018170122 PMID: 29528824

Natarajan SK, Born D, Ghodke B, Britz GW, Sekhar LN. Histopathological changes in brain arteriovenous malformations after embolization using Onyx or $\mathrm{N}$ butyl cyanoacrylate. Laboratory investigation. J Neurosurg 2009 Jul;111(1): 105-113. doi: https://doi.org/10.3171/2008.12.JNS08441. PMID: 19326974

Paramasivam S, Niimi Y, Fifi J, Berenstein A (2013) Onyx embolization using duallumen balloon catheter: initial experience and technical note. J Neuroradiol 40(4):294-302. https://doi.org/10.1016/j.neurad.2013.08.001

Pierot L, Cognard C, Herbreteau D, Fransen H, van Rooij WJ, Boccardi E, Beltramello A, Sourour N, Kupcs K, Biondi A, Bonafé A, Reith W, Casasco A (2013) Endovascular treatment of brain arteriovenous malformations using a liquid embolic agent: results of a prospective, multicentre study (BRAVO). Eur Radiol 23(10):2838-2845. https://doi.org/10.1007/s00330-0132870-6

Rose SC, Berman ZT, Fischman AM, Young LB, Flanagan S, Katz MD, Diiulio M, Kuban JD, Golzarian J (2020) Inline balloon occlusion-assisted delivery of ethylene vinyl alcohol copolymer for peripheral arterial applications: a multicenter case series. J Vasc Interv Radiol 31(6):986-992. https://doi.org/10. 1016/j.jvir.2020.01.005 Epub 2020 May 12. PMID: 32414569

Sagara K, Miyazono N, Inoue H, Ueno K, Nishida H, Nakajo M (1998) Recanalization after coil embolotherapy of pulmonary arteriovenous malformations: study of long-term outcome and mechanism for recanalization. AJR Am J Roentgenol 170(3):727-730. https://doi.org/10.2214/ ajr.170.3.9490963 PMID: 9490963

Schidlow DV, Taussig LM, Knowles MR (1993) Cystic Fibrosis Foundation consensus conference report on pulmonary complications of cystic fibrosis, Pediatr Pulmonol 15(3):187-198

Urbano J, Manuel Cabrera J, Franco A, Alonso-Burgos A. Selective arterial embolization with ethylene-vinyl alcohol copolymer for control of massive lower gastrointestinal bleeding: feasibility and initial experience. J Vasc Interv Radiol 2014 Jun;25(6):839-846. doi: https://doi.org/10.1016/j.jvir.2014.02.024. Epub 2014 Apr 19. PMID: 24755085

Velat GJ, Reavey-Cantwell JF, Sistrom C, Smullen D, Fautheree GL, Whiting J, Lewis SB, Mericle RA, Firment CS, Hoh BL (2008) Comparison of N-butyl cyanoacrylate and onyx for the embolization of intracranial arteriovenous malformations: analysis of fluoroscopy and procedure times. Neurosurgery 
63(Suppl 1):ONS73-ONS78; discussion ONS78-80. https://doi.org/10.1227/01. neu.0000335015.83616.12

Vidal V, Therasse E, Berthiaume Y, Bommart S, Giroux MF, Oliva VL, Abrahamowicz M, du Berger R, Jeanneret A, Soulez G (2006) Bronchial artery embolization in adults with cystic fibrosis: impact on the clinical course and survival. J Vasc Interv Radiol 17(6):953-958. https://doi.org/10.1097/01.RVI.0000222822.82659. 50 PMID: 16778227

Weber W, Kis B, Siekmann R, Kuehne D (2007) Endovascular treatment of intracranial arteriovenous malformations with onyx: technical aspects. AJNR Am J Neuroradiol 28(2):371-377

White RI Jr (1999) Bronchial artery embolotherapy for control of acute hemoptysis: analysis of outcome. Chest. 115(4):912-915. https://doi.org/10. 1378/chest.115.4.912 PMID: 10208183

Woo S, Yoon CJ, Chung JW, Kang SG, Jae HJ, Kim HC, Seong NJ, Kim YJ, Woo YN (2013) Bronchial artery embolization to control hemoptysis: comparison of $\mathrm{N}$ butyl-2-cyanoacrylate and polyvinyl alcohol particles. Radiology. 269(2):594602. https://doi.org/10.1148/radiol.13130046 Epub 2013 Jun 25. PMID: 23801773

\section{Publisher's Note}

Springer Nature remains neutral with regard to jurisdictional claims in published maps and institutional affiliations.

\section{Submit your manuscript to a SpringerOpen ${ }^{\circ}$ journal and benefit from:}

- Convenient online submission

- Rigorous peer review

- Open access: articles freely available online

High visibility within the field

- Retaining the copyright to your article

Submit your next manuscript at $\boldsymbol{\nabla}$ springeropen.com 